\title{
O TRABALHO DO ENFERMEIRO NOS EQUIPAMENTOS DE SAÚDE MENTAL DA REDE PÚBLICA DE CAMPINAS-SP
}

Débora Isane Ratner Kirschbaum ${ }^{1}$

Flora Karina Correa de Paula ${ }^{2}$

Kirschbaum DIR, Paula FKC. 0 trabalho do enfermeiro nos equipamentos de saúde mental da rede pública de Campinas-SP. Rev Latino-am Enfermagem 2001 setembro-outubro; 9(5):77-82.

Esta investigação objetivou verificar o campo de atuação do enfermeiro em serviços de saúde mental e analisar suas relações de trabalho com outros membros das equipes multiprofissionais, buscando verificar os nexos estabelecidos entre a prática destes profissionais e a concepção do serviço acerca do trabalho em equipe. Optou-se por realizar um Estudo de Caso de natureza qualitativa-descritiva. Observouse que o enfermeiro adquire distintas posições, conforme a organização do processo de trabalho da equipe e que o reconhecimento deste contexto é fundamental para que o profissional possa desenvolver seu trabalho de forma crítica e com boa qualidade.

PALAVRAS CHAVE: enfermagem psiquiátrica, saúde mental, equipe de assistência ao paciente

\section{THE NURSE'S WORK IN THE MENTAL HEALTH SERVICES OF THE PUBLIC SYSTEMS IN THE CITY OF CAMPINAS}

This work aimed at verifying the field of performance of nurses in the mental health services in the city of Campinas-SP as well as at analyzing their work relations with other members of the multi-professional staff as an attempt to observe the nexuses established between such professionals' practice and the service's conception concerning team work. A qualitative and descriptive investigation was conducted which used the case report as a research methodology. It was observed that nurses take different roles according to the organization of the team's work process and that the recognition of such context is essential for nursing professionals to develop their work critically and to keep high quality standards.

KEY WORDS: psychiatric nursing, mental health, patient care team

\section{EL TRABAJO DE ENFERMERÍA EN LOS SERVICIOS DE SALUD MENTAL DEL SISTEMA PÚBLICO EN EL MUNICIPIO DE CAMPINAS-SP}

Esta investigación pretendió verificar el campo de actuación del enfermero en servicios de salud mental y analizar sus relaciones de trabajo con otros miembros de los equipos multiprofesionales, buscando verificar los nexos establecidos entre la práctica de estos profesionales y la concepción del servicio a cerca del trabajo en equipo. Se optó por realizar un estudio de caso de naturaleza cualitativa-descriptiva. Se observó que el enfermero adquiere distintas conforme la organización del proceso de trabajo del equipo y que el reconocimiento de éste contexto es fundamental para que el profesional pueda desarrollar su trabajo de forma crítica y con buena calidad..

PALABRAS CLAVES: enfermería psiquiátrica, salud mental, equipo de atención al enfermo

\footnotetext{
${ }^{1}$ Enfermeira, Professor Assistente Doutor, Doutora em Saúde Mental, e-mail: isane@uol.com.br; ${ }^{2}$ Aluna do sexto semestre do Curso de Graduação em Enfermagem, Bolsista do PIBIC/CNPq. Faculdade de Ciências Médicas da UNICAMP
} 


\section{INTRODUÇÃO}

As mudanças no campo da assistência à saúde mental, ocorridas no Brasil a partir dos anos 80 , seguindo o modelo de Reforma Psiquiátrica, trouxeram a necessidade de reorganizar os serviços, criar novas modalidades de atendimento terapêutico, dentre as quais, hospitais-dia e unidades de internação em hospital geral, e reformular o modo de organização do trabalho nas equipes existentes nestes serviços, com a finalidade de se constituírem equipes interdisciplinares, onde os agentes de enfermagem pudessem assumir um caráter terapêutico em sua atuação, superando uma prática marcada pelo modelo controlador e repressor, que caracterizava o trabalho de enfermagem em psiquiatria desde seus primórdios ${ }^{(1-2)}$.

O presente trabalho teve como objetivos verificar o campo de atuação e a prática do enfermeiro em uma unidade de internação em hospital geral e em um Hospital-Dia da rede pública de Campinas$\mathrm{SP}$, bem como analisar as relações de trabalho estabelecidas por aquele profissional com os outros membros das equipes multiprofissionais, buscando verificar qual a relação entre a prática dos enfermeiros e a concepção do serviço acerca do trabalho em equipe.

\section{METODOLOGIA}

Trata-se de uma pesquisa de natureza qualitativa e descritiva, na qual utiliza-se o Estudo de Caso ${ }^{(3)}$ como método de pesquisa. A coleta de dados foi feita por meio de entrevistas não diretivas, com roteiro semi-estruturado (Anexo 1). As entrevistas foram realizadas no período de janeiro a fevereiro de 1999. Foram entrevistados cinco sujeitos, todos enfermeiros que atuam ou atuaram no Hospital-Dia (HD) do Serviço de Saúde Dr. Cândido Ferreira (SSCF) ou na Unidade Psiquiátrica (UP) do Hospital de Clínicas (HC) da Universidade Estadual de Campinas (Unicamp). Todos aceitaram participar voluntariamente da pesquisa, cientes de que sua identificação seria mantida em sigilo. Posteriormente, autorizaram a divulgação dos dados coletados por meio de termo de consentimento. Para evitar a identificação dos entrevistados, optou-se por numerar as entrevistas, por local de trabalho. Estes serviços pertencem à rede pública de atendimento em saúde do município de Campinas-SP.

A análise de dados teve como referencial teórico a Análise de Conteúdo ${ }^{(4-5)}$ e utilizou-se a "análise temática"(4-5) como técnica para tratamento do material. As entrevistas foram gravadas, transcritas posteriormente e lidas exaustivamente. Dessa forma, extraímos de cada depoimento os temas emergentes do discurso dos entrevistados os quais foram agrupados em categorias temáticas compatíveis com o referencial teórico utilizado, a fim de apreender o processo de trabalho enquanto relação social de trabalho, determinado pelo momento social, econômico e histórico.
Posteriormente, cada tema foi analisado, procurando evidenciar as relações entre o modo como o entrevistado o significa e a elaboração teórica realizada pelas pesquisadoras.

\section{CARACTERIZAÇÃO DOS SERVIÇOS UTILIZADOS PARA COLETA DE DADOS}

\section{Hospital-Dia (HD) do Serviço de Saúde Dr. Cândido Ferreira (SSCF)}

Devido à reestruturação da assistência psiquiátrica no Brasil, tem aumentado o número de hospitais-dia como alternativa terapêutica de assistência ao doente mental ${ }^{(6)}$. O HD do SSCF foi inaugurado em março de 1991, funciona de segunda à sexta-feira, das 08:00 às 17:00 hs, no subdistrito de Sousas, na cidade de Campinas. Na época da coleta de dados, atendia a uma população de 110 pacientes. A população usuária é constituída por indivíduos com diagnósticos de psicose, neuroses graves, abuso de álcool e outras drogas ilícitas. A clientela pertence a uma faixa etária de 15 a 65 anos, freqüentando a instituição por um ou mais dias da semana. Chegam à instituição por encaminhamento ou procura espontânea.

\section{Unidade Psiquiátrica do HC-Unicamp (UPHG-HC)}

As unidades psiquiátricas em hospitais gerais surgem atualmente como alternativa às internações em hospitais psiquiátricos ${ }^{(7)}$. Os primeiros leitos psiquiátricos da Unicamp surgiram quando este ainda era localizado na Santa Casa de Campinas, em 1978 , sendo quatro leitos numa enfermaria geral ${ }^{(8)}$. Essas autoras referem que a implantação do Hospital de Clínicas no prédio atual, localizado na Cidade Universitária, deu-se entre 1983-1986 e a unidade psiquiátrica foi inaugurada em dezembro de 1986 , no quarto andar do hospital, contando inicialmente, com dezoito leitos e, no momento, com dezesseis vagas que podem ser utilizadas por pacientes de ambos os sexos, de acordo com a necessidade. Os usuários, provenientes do pronto-socorro ou de outras áreas do hospital, são doentes de qualquer gravidade, voluntários ou não, agudos ou crônicos em reagudização, sendo 0 atendimento direcionado a adultos.

\section{RESULTADOS E DISCUSSÃO}

\section{Caracterização dos sujeitos}

Os sujeitos das entrevistas foram enfermeiros que atuavam nos serviços selecionados, o HD do SSCF e a unidade psiquiátrica 
UPHG do HC-Unicamp. Foram entrevistados, no total, cinco enfermeiros sendo duas enfermeiras que atuavam no HD do SSCF, duas enfermeiras e um enfermeiro que trabalhavam na UPHG do HC-Unicamp (um profissional de cada turno - manhã, tarde e noite). As enfermeiras que haviam trabalhado no HD tinham experiência prévia em outros serviços de atendimento em saúde mental, antes de ingressarem nesta instituição, enquanto a do UPHG/HC foi o primeiro emprego em psiquiatria para os enfermeiros entrevistados deste serviço. Quanto à formação específica em saúde mental, constatou-se que três enfermeiros possuíam especialização e/ou residência e cursos dirigidos à área (formação em psicodrama, grupos operativos, leitura psicanalítica) feitos após a graduação em enfermagem (as duas enfermeiras do HD e um enfermeiro da enfermaria de psiquiatria), dois dos enfermeiros haviam feito outro curso de graduação, sendo um profissional que atuou no $\mathrm{HD}$ formado em Psicologia e um enfermeiro da UPHG formado em Farmácia.

O tempo de graduação variou de quatro a treze anos: dois enfermeiros tinham menos de cinco anos de formados (ambos exerciam atividades na UPHG) e três enfermeiros (dois do HD e um da enfermaria psiquiátrica) haviam completado a graduação em enfermagem num período superior há dez anos. 0 tempo de trabalho nos equipamentos selecionados variou de três a onze anos. As entrevistas reproduzidas, serão identificadas na ordem cronológica de sua realização e trazendo a identificação do serviço: HD para o HD do SSCF e UP para a UPHG do HC-Unicamp.

\section{Atribuições dos enfermeiros}

É possível caracterizar o trabalho de enfermagem nos referidos serviços através dos discursos que os enfermeiros enunciam sobre suas atribuições. A caracterização do trabalho do enfermeiro pode ser feita a partir da identificação de suas finalidades: a tecnologia utilizada para a realização do trabalho, ou seja, os modos de produção, e o objeto de sua ação ${ }^{(9)}$. Constatamos que, no HD-SSCF, os enfermeiros desempenhavam atividades de assistência direta e indireta, através de ações individuais e coletivas, atingidas em diferentes intervenções, conforme pode-se ler nos trechos de depoimentos reproduzidos a seguir:

Eu era responsável pelo programa dos alcoolistas, de tratamentos dos alcoolistas (...) fazia os grupos verbais, atividades especificas, fazia atendimentos de familia (...) e ficava responsável pela triagem. Também tinha o periodo de triagem, que eu era responsável, e, às vezes, tinha algumas outras (atividades), outros pacientes que eu acabava me tornando referência ... (entrevista 1-HD)

Olha, no Cândido Ferreira, eu coordenava o grupo de alcoolistas, coordenava o grupo de psicóticos, coordenava um grupo de familiares de psicóticos e neuróticos graves; eu atendia individual, atendia alguns pacientes em atendimentos individual... (entrevista $2-\mathrm{HD}$ )
Na UPHG do HC-Unicamp, as atribuições do enfermeiro estão mais ligadas ao cuidado de enfermagem no âmbito individual, visto que este serviço se caracteriza por cuidar da medicação, higiene e cuidados clínicos individuais. A função da enfermagem é cuidar do indivíduo sadio ou doente, família ou comunidade, com o intuito de promover , manter ou recuperar a saúde ${ }^{(9)}$. A realização das funções de cuidar e administrar ao nível individual atende às necessidades do modelo clínico de assistência à saúde, que marca a enfermagem hospitalar $^{(9)}$, e que é o observado na Unidade de Psiquiatria. Neste modelo, as ações de enfermagem são subordinadas ao saber médico, e o desenvolvimento dessas ações visa facilitar o processo de cura.

No HD do SSCF, constata-se que o modelo que norteia as ações dos enfermeiros e demais profissionais não é mais o Modelo Clínico, mas a chamada Reabilitação Psicossocial.

Esse modelo Psicossocial ou de Reforma Psiquiátrica caracteriza-se por enfatizar o processo de reprodução de saúde e de reinserção social do paciente, ou seja, entende-se que a saúde existe em formas distintas, não é um conceito aplicável para todas as pessoas da mesma forma ${ }^{(10)}$. Além disso, no HD do SSCF, as ações devem ser realizadas de forma a considerar os relatos e atitudes dos pacientes, a partir da apreensão de seus significados, tendo como base a teoria psicanalítica ${ }^{(6)}$.

É interessante notar que os meios de produção desse trabalho são subordinados à concepção que o serviço adota acerca do fenômeno do adoecer. Assim, conforme pode-se depreender dos depoimentos anteriores, no HD do SSCF, desenvolvem-se atividades grupais, programas dedicados à determinadas morbidades (alcoolistas, por exemplo), psicodrama, sistema de profissionaisreferências, atendimento individual, medicação. Enquanto isso, na UPHG do HC-Unicamp, a terapêutica utilizada compreende o cuidado clínico (curativos, medicamentos), a contenção verbal, química ou mecânica, medidas de vigilância e controle, segundo se pode concluir a partir dos seguintes depoimentos:

A gente tem a função de controlar mesmo a enfermaria (...) observação de como está agindo o paciente, tá? Eu vejo assim. Aqueles que, teoricamente têm que dormir (...) Essa é uma das funções, a outra delas é prá gente estar vendo, é você estar prescrevendo, ou inclusive, notificando toda alteração de comportamento do paciente (...) Se tem alguma coisa da clínica, a gente assume, tá? Curativos, soroterapia (...) Uma das atribuições que o pessoal fala, que pode ser colocada é ao nível de contenção do paciente... (entrevista 3-UP)

A gente lida com os cuidados, com a parte de higiene do paciente (entrevista 4-UP)

Entretanto, envolvem-se também com a implementação do relacionamento interpessoal enfermeiro-paciente, entendido e descrito por um dos profissionais da seguinte maneira: você tem que ter uma..., assim, um tempo maior com o paciente, prá conversar, ficar mais do lado, ter um contato... (entrevista 5-UP) 
Além da assistência direta, os enfermeiros realizam atividades relacionadas com 0 atendimento indireto do usuário, que seriam, em ambos serviços, as atividades de supervisão. Agrupamos as atividades referentes à supervisão em supervisão clínica (avaliação de casos, estudo da teoria); administrativa ou estratégica (avaliação de metas, planejamento de intervenções); institucional (análise de processos cotidianos dos serviços) e de suporte pessoal (elaboração da subjetividade e vivências cotidianas) ${ }^{(11)}$. Consideramos que nem todos os tipos de supervisão estão presentes nos dois serviços.

No HD do SSCF, notamos traços dos modelos clínico e estratégico, como vê-se a seguir:

Era um sentido de supervisão com as gurias da medicação, colher o exame de sangue, do manejo com o paciente, de tá explicando que é o caso, porque ele delira, o que que é uma alucinação, mais nesse sentido (entrevista 1. HD)

$\mathrm{Na}$ UPHG do HC, os enfermeiros tinham que assumir o controle do ambiente, a elaboração de escalas de plantões e a identificação de necessidades de recursos humanos e materiais. Portanto, aqui, a supervisão é compreendida num sentido bastante diferente daquele que foi apontado ${ }^{(11)}$. 0 que aparece nos depoimentos já havia sido identificado por investigações realizadas por enfermeiros ${ }^{(9)}$, ou seja, que o enfermeiro, no modelo médicoclínico, desenvolve atividades administrativas, utilizando para esse fim modelos e métodos de administração, normas e rotinas, a força de trabalho em enfermagem (os auxiliares), os equipamentos e materiais permanentes e aqueles para administração de drogas e soluções. Para essas autoras ${ }^{(9)}$, a finalidade dessas ações está em controlar e organizar o processo de trabalho e a, longo prazo, consiste em favorecer a cura através do cuidado de enfermagem.

Constatamos também que a finalidade assistencial nos dois serviços, obviamente, é diferente, ainda, conforme a concepção que se faz do processo do adoecer. Assim, de acordo com os sujeitos do Hospital-Dia, a finalidade do cuidado está na reinserção social dos sujeitos:

Com os alcoolistas, os objetivos, primeiro era deles conseguirem chegar à abstinência e, a partir desse ponto reorganizar a vida deles. Então, era assim, tentar levar a consciência da doença e aprender a lidar com ela. Eu sei que eu tenho uma doença, agora eu conheço como ela é, como é que eu vou lidar com ela a partir desse ponto. $E$ a partir do momento que o paciente consegue ter essa clareza, ele aprenderia a lidar com isso fora, ou seja, ele poderia receber alta e estar indo embora (entrevista 1-HD)

O estudo realizado sobre a UPHG do $\mathrm{HC}^{(7)}$ corrobora os dados obtidos nas entrevistas com os enfermeiros, que afirmavam que a finalidade da assistência está na melhora do quadro agudo, conforme exemplifica um dos depoimentos coletados:
O objetivo é tirar ele desse quadro agudo (...) é tirar ele dessa crise aguda que está acontecendo no momento (entrevista 3 - UP)

A partir da definição da finalidade da assistência, percebemos também de que maneira estes profissionais definem seu objeto de trabalho. Para os profissionais do HD do SSCF, tal objeto consiste na diminuição do sofrimento psíquico, que para estes profissionais significa torná-lo suportável, ainda que não se possa suprimí-lo, uma vez que as enfermeiras o consideram inerente à vida das pessoas:

O objetivo da minha assistência, acho que era acima de tudo, possibilitar às pessoas que chegam lá em sofrimento, a diminuição do sofrimento (entrevista 2-HD)

O que dá para você perceber e saber que hoje as pessoas estão muito mais doentes, assim, nem tão graves, a gente está muito mais neurótico hoje, com muito mais conflitos, mais agressividade (entrevista 1 - HD)

Na UPHG, o objeto da assistência é a crise do indivíduo internado. Porém, em momento nenhum os entrevistados que ali atuam definem o que entendem pelo termo crise, ao qual eles se referem e baseiam a sua ação.

\section{Relações de trabalho}

A equipe é organizada conforme uma divisão do saber/ poder dentro da instituição ${ }^{(2)}$. Quando se considera que a doença não tem uma causa única, mas é determinada por diversos fatores que o saber médico, da forma como é instituído, não consegue intervir de forma satisfatória, percebe-se a importância de se organizar uma equipe com diversos profissionais que não estejam subordinados à hegemonia do saber médico. Divide-se a organização do saber considerando o grau de coordenação, cooperação e intensidade da troca entre os especialistas ${ }^{(12)}$. Conforme afirmamos, a distribuição de saber determina uma forma de organização da equipe, de modo a atender às necessidades levantadas no atendimento do usuário. Deste modo, agrupamos a forma de organização de equipe segundo a visão que adota-se de interação entre disciplinas e entendida por nós como o saber, ou seja, apropriação de um conhecimento, específico de cada área ${ }^{(13)}$. Seguindo o referido modelo, conceituamos as equipes multiprofissionais dos serviços pesquisados em multidisciplinares e interdisciplinares.

Na UPHG do HC-Unicamp, a equipe se organiza de modo multidisciplinar, aqui entendido como um conjunto de disciplinas que tratam de uma questão comum sem que os profissionais implicados estabeleçam entre si efetivas relações no campo teórico e científico ${ }^{(13)}$. A coordenação se dá na ordem administrativa e a comunicação, geralmente, se faz por anotações em prontuários únicos. Na UPHG do $\mathrm{HC}$, isso foi possível ser percebido durante o período de estágio e 
observação. Um exemplo do processo de organização da equipe é dado pelo enfermeiro ao falar sobre seu relacionamento com a equipe terapêutica:

Eu considero bom, mas eu acho que uma coisa que deixa tudo a desejar, é que como eu trabalho à tarde e a equipe terapêutica se reuni de manhã, a gente se distancia um pouco, tá? Como eu não tenho nenhuma atividade de manhã, eu passei a vir às quintas-feiras pela manhã, onde eu pudesse ficar mais próxima da equipe e estar trazendo informações, discutindo casos de pacientes (...) porque à tarde, eles têm outras atividades, mas a gente tenta engajar conforme dá e têm as enfermeiras da manhã, que quando não dá para a gente participar das reuniões, elas acabam passando as informações em passagem de plantão, mas isso acaba se perdendo um pouco. (entrevista 4-UPHG)

No que diz respeito às relações entre as diversas disciplinas e profissões ou à aproximação dos diferentes saberes em jogo na equipe multidisciplinar, nota-se que não se trata aqui de uma troca, nem tampouco de uma relação horizontal entre diferentes saberes e seus agentes, mas sim da valorização de um saber em relação ao outro, supostamente mais estruturado ou de maior valor ao qual o outro deve equiparar-se. 0 trecho a seguir ilustra bem o que foi dito: O que eu procuro que influencie é, se eu trabalho com os auxiliares, é claro que o enfermeiro, ele acaba sendo um espelho (...) (entrevista 4-UP)

Já no HD do SSCF, a equipe se relaciona de forma interdisciplinar, onde a interdisciplinaridade é entendida como estrutural, havendo reciprocidade, enriquecimento mútuo, com uma tendência à horizontalização das relações de poder entre os campos implicados $^{(13)}$

Este conceito exige a identificação de uma problemática comum, com definição de uma base teórica na qual orientar suas ações, universalizando princípios e concepções, gerando uma aprendizagem mútua, que não se faz por somatória de conhecimentos, mas por construção de um novo conhecimento compartilhável com todos os membros da equipe. $E$, ainda, exige a nomeação de um conhecimento como integrador e coordenador do campo interdisciplinar.

Nos depoimentos abaixo, é possível identificar características de interdisciplinaridade na construção de um novo saber que a enfermagem adquiriu:

(...) as práticas se juntaram e contribuíram, tanto é que montou o programa, eu trouxe idéias, ela trouxe idéias, e a maneira de lidar das duas tinha diferenças (...) Com o passar do tempo, ela se tornou mais durona e eu mais flexível, teve troca, né? (entrevista 1-HD)

(...) referência no sentido de estar influenciando eles (outros membros da equipe) a estarem trabalhando de uma forma que eu já conhecia (entrevista 2-HD)
As dificuldades relacionadas à esses modos de organização de equipe, aparecem nos discursos dos profissionais. No HD do SSCF, a enfermagem adquiriu um saber novo, construído a partir da prática interdisciplinar. A aquisição dessa nova forma de trabalho, tornou o profissional mais autônomo, já que se apropriou das características de outros profissionais. Entretanto, essa dita autonomia leva ao isolamento da equipe como um todo, tornando, paradoxalmente, o profissional especializado em atender ao grupo com quem trabalha, mas perdendo a visão do processo de atenção como um todo:

(...) eu perdi um pouco esse acompanhamento que antes eu tinha e aí, eu fiquei, eu percebi assim, que eu fiquei mais isolada. (...) eu tinha um pouco de dificuldade de participar da discussão, porque eu lidava direto com os alcoolistas e, às vezes, a discussão era sobre pacientes psicóticos (...) (entrevista 1-HD)

Já na UPHG do HC, o modo de organização de equipe pressupõe a hierarquização de saber. A enfermagem subordina-se ao trabalho médico ao mesmo tempo em que o enfermeiro concentra o saber/poder dentro da equipe de enfermagem e visa uniformizar os sujeitos para prestar o cuidado de enfermagem, conforme se lê a seguir:

(...) não sei se tem o perfil ou não para trabalhar em psiquiatria (...) então o que é ter perfil? É ter uma arma especifica, um protocolo especifico prá você estar avaliando se a pessoa é ideal para trabalhar em psiquiatria. (entrevista 3-UP)

(...) o funcionário acaba repetindo mais ou menos, aquilo que você faz (...) (entrevista 3-UP)

\section{CONSIDERAÇÕES FINAIS}

Esta pesquisa permitiu verificar que as características assumidas pelo trabalho de enfermagem nas equipes de saúde mental adquirem diferentes contornos, não só pelo tipo de atividades e de atribuições assumidas pelos enfermeiros, como também pela posição que eles ocupam no conjunto do processo de trabalho da equipe, seja ela multidisciplinar ou interdisciplinar nos dois diferentes equipamentos analisados, os quais, por sua vez, expressam distintos modelos de intervenção ${ }^{(14)}$. O não reconhecimento destas condições relacionadas a sua inserção e posição na equipe, decorrentes da articulação entre o seu trabalho, o modelo de intervenção e o modelo assistencial em que ele está inserido pode levar o enfermeiro a se empenhar num ativismo acrítico e desenvolver práticas pouco fundamentadas teoricamente, o que não contribui para melhorar nem a assistência de enfermagem, nem a assistência em saúde mental. 
Anexo 1

\section{ROTEIRO DE ENTREVISTA}

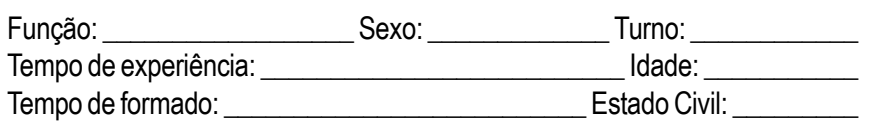

1. Qual a sua formação em Saúde Mental?

2. Há quanto tempo atua na área? Em quais serviços de psiquiatria já trabalhou?

\section{REFERÊNCIAS BIBLIOGRÁFICAS}

1. Rocha RM. Enfermagem psiquiátrica: que papel é este? Rio de Janeiro (RJ): Instituto Franco Basaglia: Editora TeCorá; 1994.

2. Kirschbaum DIR. The Participation of nursing in a project of desinstitucionalization. Abstracts of the $10^{\text {th }}$ World Congress of Psychiatry; 1996 August 23-28; Madrid; Spain 1996.

3. Triviños ANS. Introdução à pesquisa em ciências sociais: a pesquisa qualitativa em educação. São Paulo (SP): Atlas; 1995.

4. Minayo MCS. O desafio do conhecimento: pesquisa qualitativa em saúde. São Paulo (SP): Hucitec/Abrasco; 1994.

5. Bardin L. Análise do conteúdo. Lisboa: Editora 70; 1994.

6. Campos CMS. Consolidando a Reforma Psiquiátrica no Brasil através dos Hopitais-Dia: a emergência de contradições entre a intencionalidade e a operacionalidade. [dissertação]. São Paulo (SP):

Escola de Enfermagem/USP; 1998.
3. O que acha do atendimento psiquiátrico no hospital geral? E em outros serviços nos quais não há internação do doente?

4. Quais as maiores dificuldades que você sente ao prestar assistência aos pacientes psiquiátricos?

5. Quais os motivos dessas dificuldades?

6. Como é o seu relacionamento com outros membros da equipe terapêutica?

7. Quais são as suas atribuições no que se refere à assistência do doente?

8. Como é estruturada essa instituição onde você trabalha?

9. O que você pensa sobre o campo de enfermagem psiquiátrica?

10. Qual sua visão a respeito de doença mental?

7. Botega NJ, Dalgalarrondo P. Saúde mental no hospital geral espaço para o psíquico. São Paulo (SP): Hucitec; 1993.

8. Machado AL, Cabral MAA. Enfermarias de psiquiatria em hospital geral: duas experiências na visão de uma enfermeira. J Bras Psiquiatria 1997 junho; 46(6):319-23.

9. Almeida MCP, Rocha SMM. Considerações sobre a enfermagem enquanto trabalho. In: Almeida MCP, Rocha SMM, organizadoras. 0 trabalho de Enfermagem. São Paulo (SP): Cortez; 1997. p.15-26.

10. Macedo ALP, Maron MGR. A clínica e a reforma psiquiátrica: um novo paradigma? J Bras Psiquiatria 1997 maio; 46(4):205-11.

11. Vasconcelos EM. Desinstitucionalização e interdisciplinaridade em saúde mental. Cadernos IPUB 1997; 1(7):19-42.

12. Feriotti ML. A questão da interdisciplinaridade na saúde. Rev Médica Puccamp 1995; 4(3):130-32.

13. Almeida N Filho. Transdiciplinaridade e saúde coletiva. Ciência \& Saúde Coletiva 1997; 2(1-2):5-19.

14 - Mehry EE. A saúde pública como política: um estudo sobre reformuladores de políticas. São Paulo(SP): Hucitec; 1992. 